\title{
MiR-423-5p may regulate ovarian response to ovulation induction via CSF1
}

\author{
Shi Xie ${ }^{1,2}$, Qiong Zhang ${ }^{1,2}$, Jing Zhao ${ }^{1,2}$, Jie Hao ${ }^{1,2}$, Jing $\mathrm{Fu}^{1,2}$ and Yanping $\mathrm{Li}^{1,2^{*}}$
}

\begin{abstract}
Background: We have previously shown that hsa-miR-423-5p expression in ovarian granulosa cells is decreased in high ovarian response populations. The objective of the present study was to find the target gene and mechanism for miR-423-5p involved in ovarian response regulation.

Methods: (a) TargetScan was used to predict the target gene of hsa-miR-423-5p. (b) A model for hsa-miR-423-5p overexpression or inhibition was constructed by transfecting KGN cells with lentivirus. CSF1 mRNA and protein expression and luciferase activity were measured. (c) The cell cycles of control and lentivirus treated KGN cells were analyzed. Western blot was used to measure the expression of CDKN1A in KGN cells. (d) The concentration of $E_{2}$ in KGN cell culture medium were measured.
\end{abstract}

Results: (a) TargetScan revealed that the $3^{\prime}$ un-translated region of CSF1 matched 11 bases at the 5' end of miR423-5p, making it a likely target gene. (b) Overexpression or inhibition of miR-423-5p were associated with respective decreases or increases in CSF1 expression (both mRNA and protein) $(p<0.05)$ and luciferase activity $(p<$ 0.05). (c) When miR-423-5p expression increased, the number of G0/G1 phase cells and the expression of CDKN1A protein increased while estradiol concentrations in the cell culture solution decreased $(p<0.05)$. However, when miR-423-5p expression decreased, the number of $S$ phase cells increased and E2 concentrations increased while the expression of CDKN1A protein decreased $(p<0.05)$.

Conclusions: Colony stimulating factor 1 is a target gene of miR-423-5p and that it may regulate ovarian response to ovulation induction by affecting granulosa cells proliferation and estrogen secretion.

Keywords: miR-423-5p, CSF1, Follicular development, In vitro fertilization (IVF)

\section{Background}

Controlled ovarian stimulation (COS) is one of the key steps in in vitro fertilization (IVF), in which exogenous gonadotropins are used to induce the growth and development of multiple follicles during an ovarian cycle. However, due to the different sensitivities of patients to ovulation-promoting drugs, ovarian response significantly varies among different individuals, and even within the

\footnotetext{
* Correspondence: lyp7798@126.com

'Reproductive Medicine Center, Xiangya Hospital, Central South University, 87 Xiangya Road, Changsha, Hunan, China

${ }^{2}$ Clinical Research Center For Women's Reproductive Health In Human Province, Changsha, Hunan, China
}

same individual between different cycles [1]. In our previous study [2], we found that miR-423-5p expression in the granulosa cells of patients with high ovarian response to exogenous gonadotropins (the patients who had over 14 oocytes retrieved in IVF treatment, hereinafter referred to as "ovarian hyperresponders") decreased significantly, suggesting that it may play an important role in the regulation of ovarian response. Indeed, MiR-423-5p may alter the expression level of its target genes to cause changes in the number and function of granulosa cells and may increase the sensitivity of ovarian hyperresponders to ovulationinducing drugs. Some researchers have found that miR423-5p is important in the development of tumor cells, it can regulate tumor cell proliferation and increase their

(c) The Author(s). 2020 Open Access This article is licensed under a Creative Commons Attribution 4.0 International License, which permits use, sharing, adaptation, distribution and reproduction in any medium or format, as long as you give appropriate credit to the original author(s) and the source, provide a link to the Creative Commons licence, and indicate if changes were made. The images or other third party material in this article are included in the article's Creative Commons licence, unless indicated otherwise in a credit line to the material. If material is not included in the article's Creative Commons licence and your intended use is not permitted by statutory regulation or exceeds the permitted use, you will need to obtain permission directly from the copyright holder. To view a copy of this licence, visit http://creativecommons.org/licenses/by/4.0/ The Creative Commons Public Domain Dedication waiver (http://creativecommons.org/publicdomain/zero/1.0/) applies to the data made available in this article, unless otherwise stated in a credit line to the data. 
invasiveness $[3,4]$. To the best of our knowledge, no study has reported the role of miR-423-5p in regulating ovarian response.

MicroRNA (miRNA) is an endogenous non-coding small RNA that measures about 21-25 nucleotides. It is involved in post-transcriptional gene regulation by targeting mRNAs for expression, degradation, or translational repression $[5,6]$. These miRNAs play key roles in various physiological activities, such as cell proliferation, differentiation, apoptosis, migration, and metabolism. Studies have also shown that miRNA expression is closely related to the regulation of ovarian function: miR-27a-3p, miR-132, miR-133b, miR-212, and miR224 are involved in regulating ovarian hormone secretion [7-14]; miR-21, miR-15a, miR-105, miR-141-3p, and miR-143 are involved in regulating ovarian cell proliferation and apoptosis [15-24]; and miR-130b, miR-224, miR-378, and miR-383 are involved in regulating follicular growth and egg maturation [25-32]. However, few studies have focused on the link between miRNAs and ovarian response, which is key to ovarian function.

Ovarian granulosa cells play an important role in the regulation of follicular development [33]. There are abundant receptors on the surface of granulosa cells, such as follicle-stimulating hormone (FSH), luteinizing hormone $(\mathrm{LH})$, and estrogen receptors. When FSH binds to granulosa cell surface receptors, it stimulates granulosa cell proliferation and aromatase activity and promotes estradiol $\left(\mathrm{E}_{2}\right)$ synthesis and secretion. Estrogen and FSH synergistically upregulate FSH and LH receptor expressions on granulosa cell surface, further promoting $E_{2}$ synthesis and allowing rapid follicle growth [34, 35]. The granulosa-like tumor cell line, KGN, originated from a 63-year-old Japanese woman with a Stage III granulosa cell carcinoma in 1984 and is often used to study the function of human granulosa cells [36]. Compared with primary cultured granulosa cells, KGN cells have a stable genetic background; furthermore, the experimental results obtained with the latter are unaffected by individual differences and are easy to repeat, making the results more accurate and reliable.

In the present study, we used TargetScan to predict the possible target genes of hsa-miR-423-5p, before seeking to verify the target gene by dual luciferase reporter gene system, quantitative real-time polymerase chain reaction (qRT-PCR), Western blot, and other techniques in KGN cells. In addition, we explored the role and mechanism of hsa-miR-423-5p and its target gene in regulating ovarian response to ovulation induction. We specifically hypothesized that miR-423-5p altered abundance of proteins involved in ovarian granulasa cells proliferation and estrogen secretion.

\section{Materials and methods MicroRNA target gene prediction}

The TargetScan software was developed by Lewis et al. [37] and is used to predict the target genes of mammalian miRNAs. It is the first generation of predictive software and uses an algorithm designed according to the basic rules of seed complementation. Target genes are predicted based on the inter-species conservation of miRNA target mRNA sequences. TargetScan introduced the false positive rate for the first time to evaluate the prediction results. The software predicts that a given target gene has a low false positive rate and is widely used in the prediction of miRNA target genes. This study was conducted using the TargetScan database (http://www.targetscan.org/) combined with a literature review to predict the potential target genes for miR-423-5p.

\section{KGN cell culture and transfection}

Granulosa-like tumor cell line KGN cells were donated by Professor Xu Wenming from the Second Hospital of West China, University of Sichuan. All cells were cultured in Dulbecco's modified Eagle's medium (DMEM/ F12; HyClone, USA) containing 20\% fetal bovine serum (Sijiqing, China) and 1\% antibiotics (Streptomycin, Penicillin; Gibco, USA). The cells were incubated in a humidified incubator maintained at $37^{\circ} \mathrm{C}$ with $5 \% \mathrm{CO}_{2}$, and the culture medium was replaced every $24 \mathrm{~h}$. After $24 \mathrm{~h}$ of cultivation, the cells have grown adherently, most of them were round, and a few were fusiform or polygonal, dark particles can be seen on the cell surface. After $48 \mathrm{~h}$, the cells proliferated significantly, they were uniform in size, spread evenly in a six-well plate, and were fusiform or polygonal. The elongated pseudopods of cells were connected to each other and the particles in the cytoplasm were abundant. Cells were seeded at $1 \times$ $10^{5}$ cells per well in a six-well plate prepare for transfection when the cells were growing well. Independent experiments were repeated in triplicate.

MicroRNA lentiviral vectors, including hsa-miR-423 expression vector (hereinafter referred to as "lentivirus") and the control, hsa-miR-423-5p inhibitor (hereinafter referred to as "inhibitor") and the control, were used to transfect KGN cells. All viral vectors were designed and supplied by the GeneCopoeia company (USA; catalog no. LPP-HmiR0276-MR03, LPP-CmiR0001-MR03, LPPHmiR-AN0492-AM03, and LPP-CmiR-AN0001-AM03). After removing the old culture solution and the corresponding miRNA lentiviral suspension were separately added to the KGN cells. Gently mix to bring the virus suspension into contact with the cells, and incubate in a $5 \% \mathrm{CO}_{2}, 37^{\circ} \mathrm{C}$ incubator for $48 \mathrm{~h}$. Cells were harvested for qRT-PCR and Western blot analysis. 


\section{Quantitative real-time polymerase chain reaction (qRT-} PCR)

Total RNA was extracted from the KGN cells with Trizol reagent (Sigma, USA), and miR-423-5p expression was measured using an All-in-One ${ }^{\text {TM }}$ miRNA qRT-PCR Detection Kit (GeneCopoeia, USA), each following the manufacturer's protocols. Target gene expression was measured by an All-in-One ${ }^{\text {tw }}$ First-Strand cDNA Synthesis Kit (GeneCopoeia, USA) and an All-in-One qPCR Mix (GeneCopoeia, USA). For normalization, U6 (a small nuclear RNA) was used as the endogenous control for hsa-miR-423-5p and GAPDH was used as the endogenous control for the target gene, respectively. The cycle threshold $(\mathrm{Ct})$ was defined as the number of cycles required for the fluorescent signal to cross the threshold in real-time PCR, and $\triangle \mathrm{CT}$ was calculated by subtracting the $\mathrm{Ct}$ values of the internal control from the $\mathrm{Ct}$ values of the corresponding gene. Finally, relative expression levels were determined by the $2^{-\Delta \Delta \mathrm{Ct}}$ method [38]. The relative expression levels of miRNA and mRNA in each sample were tested in triplicated.

\section{Western blotting analysis}

After the medium was aspirated, the cells were washed twice with phosphate-buffered saline (PBS), before adding the RIPA buffer (Thermo, 89,900, USA) to lyse the cells fully. The lysed cell fluid was added to a $1.5 \mathrm{~mL}$ centrifuge tube and centrifuged at $12,000 \times \mathrm{g}$ for $1 \mathrm{~min}$ at $4{ }^{\circ} \mathrm{C}$. The protein concentration was determined by a BCA protein assay (Thermo, USA). Protein were separated on $10 \%$ sodium dodecyl sulfate-polyacrylamide gel electrophoresis and transferred to a polyvinylidene difluoride membrane. We then prepared $5 \%$ skim milk powder as a blocking solution with $1 \times \mathrm{PBST}$ (PBS + $0.2 \%$ Tween-20) (Sigma, USA). The protein membrane was rinsed, transferred to the blocking solution, and shaken slowly on a shaker at room temperature for 60 min. The blocking solution was aspirated, and the diluted primary antibody (1:1000, Santa Cruz, sc-365,779, USA) was added and incubated overnight at $4{ }^{\circ} \mathrm{C}$. Then the membranes were washed three times and incubated with diluted rabbit anti-mouse IgG-HRP (1:6000, Santa Cruz, sc-358,917, USA) for $1 \mathrm{~h}$. After washing three times with PBST, we detected the protein signal using Clarity Western ECL Substrate (Bio-Rad Laboratories, USA).

\section{Dual luciferase reporter assay}

The 3' untranslated region (UTR) of the colony stimulating factor 1 (CSF1) mRNA containing the miR-423-5p binding site was cloned into the restriction sites of a CSF1 luciferase reporter vector. This work was done by GeneCopoeia (catalog no. HmiT003149-MT06). KGN cells transfected with miR-423 lentivirus or inhibitor $\left(1 \times 10^{5}\right)$ were seeded into 24-well plates and cotransfected with reporter or control plasmid (provided by GeneCopoeia; catalog no. CmiT000001-MT06). Luciferase assay was assessed using the Luc-Pair ${ }^{\text {Tu }}$ DuoLuciferase Assay Kit (GeneCopoeia, USA), following the manufacturer's instructions. Three wells of cells were used per group.

\section{Cell-cycle analysis}

We harvested control and lentivirus treated KGN cells. EDTA-free trypsin was added to the cells, and the mixture was centrifuged at $750 \times g$ for $5 \mathrm{~min}$ and washed twice with cold PBS. Then, the cells were fixed in icecold $70 \%$ ethanol overnight at $4{ }^{\circ} \mathrm{C}$. The next day, the cells were centrifuged briefly and washed twice with PBS, before being resuspended in PBS buffer containing RNase A and incubated at $37^{\circ} \mathrm{C}$ for $30 \mathrm{~min}$ in the dark. The cells were then stained with propidium iodide at room temperature for $30 \mathrm{~min}$, kept in the dark, and processed in a BD LSRFortessa ${ }^{\mathrm{Tm}}$ flow cytometer (BD Biosciences, USA). About $1 \times 10^{5}$ cells were used to analyze the stage of the cell cycle. Independent experiments were repeated in triplicate.

\section{Estradiol assay}

Cell culture medium $\left(1 \times 10^{5}\right.$ cells $)$ was collected, centrifuged, and the supernatant was extracted. Electrochemiluminescence immunoassay (ECLIA) was used to measure the $E_{2}$ concentration. ECLIA was performed on Roche Cobas E601 equipment (Roche, Swit). The reagent used in the equipment was Roche's estradiol detection reagent (Roche, 03000079122, Swit). It contains streptavidin-coated magnetic microparticles $(0.72 \mathrm{mg} /$ $\mathrm{ml})$, biotinylated rabbit anti-estradiol antibody $(45 \mathrm{ng} / \mathrm{l})$ and $\mathrm{Ru}$ (bpy) $32+$ labeled estradiol-peptide $(2.75 \mathrm{ng} / \mathrm{ml})$. Samples and reagents were loaded in the equipment at relevant positions. The sample volume used for detection of $E_{2}$ by ECLIA was $35 \mu \mathrm{l}$. The ECLIA were performed as the manufacturer's instructions. Once sample is loaded the equipment automatically performed and released the results. For ECLIA calibrators and controls were run as manufacturer's protocol. The measurement interval was $5.00-4300 \mathrm{pg} / \mathrm{ml}$. The intra and inter coefficients of variation were $1.4-4.9 \%$. The assay was repeated three independent times.

\section{Statistical analysis}

All quantitative data are presented as means \pm standard error of the mean, with at least three biological replicates used per analysis. Two-tailed Student's t-test was utilized to analyze the significance of difference between two groups, whereas categorical data were analyzed using the $X^{2}$ or Fisher exact tests. $P<0.05$ was considered to indicate a statistically significant difference. All 
statistical analyses were performed using PASW Statistics for Windows, Version 18.0 (SPSS, Inc., Chicago, IL, USA).

\section{Results}

CSF1 is the predicted target gene of hsa-miR-423-5p

Transfection efficiency exceeded $85 \%$ by microscopy 48 $\mathrm{h}$ after the KGN cells were transfected with the hsamiR-423-5p lentivirus. Of note, transfection with the lentivirus or inhibitor caused hsa-miR-423-5p expression to be increased or decreased in KGN cells, respectively (Supplemental Fig. 1a). It was predicted that hsa-miR423-5p targeted CSF1, an important cytokine involved in regulating macrophage proliferation, differentiation, and function. The predicted sequences to which hsa-miR423-5p binds in the 3'-UTR of CSF1 are shown in Supplemental Fig. 1b.

\section{Hsa-miR-423-5p negatively regulates the expression of CSF1}

Western blot assays and qRT-PCR further indicated that hsa-miR-423-5p negatively regulates the expression of CSF1, in KGN cells (Fig. 1c, d; $P<0.05$ ). Accordingly, when KGN cells were transfected with hsa-miR-423 lentivirus, the expressions of CSF1 mRNA and protein both decreased significantly. By contrast, when KGN cells were transfected with the hsa-miR-423-5p inhibitor, the expressions of CSF1 mRNA and protein increased significantly.

\section{Dual luciferase reporter gene confirmed that CSF1 is a target gene of hsa-miR-423-5p}

Next, we examined whether hsa-miR-423-5p could directly regulate CSF1 expression in the under- or overexpression of hsa-miR-423-5p KGN cells. Our results show that firefly luciferase activity was significantly decreased in the hsa-miR-423-5p overexpression KGN cells (Fig. 2a) and was significantly increased in the hsa-miR423-5p under-expression KGN cells compared with the control cells (Fig. 2b). These data provide strong evidence that the hsa-miR-423-5p inhibits CSF1 gene expression by directly binding to sites within the 3 '-UTR of CSF1.

\section{Hsa-miR-423-5p could influence cycle proliferation of KGN cells}

To understand the role of hsa-miR-423-5p in modulating the cell cycle of KGN cells, we performed flow cytometric analysis after transfection of the hsa-miR-423-5p lentivirus or inhibitor. Overexpression of hsa-miR-423$5 p$ resulted in a significant increase $(P<0.01)$ in the percentage of cells in the G0/G1 phase compared with the negative control cells (Fig. 3). This result indicated that overexpression of hsa-miR-423-5p could induce KGN
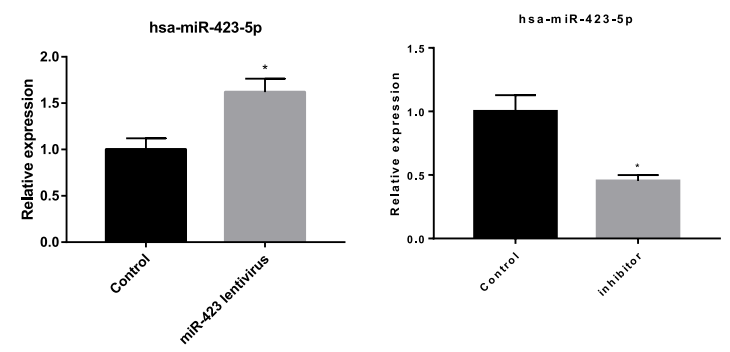

b
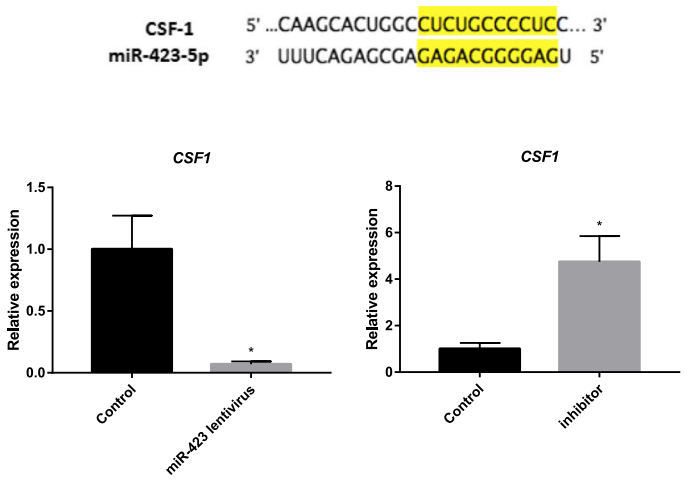

d

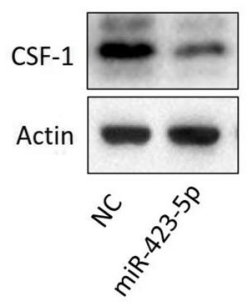

CSF1
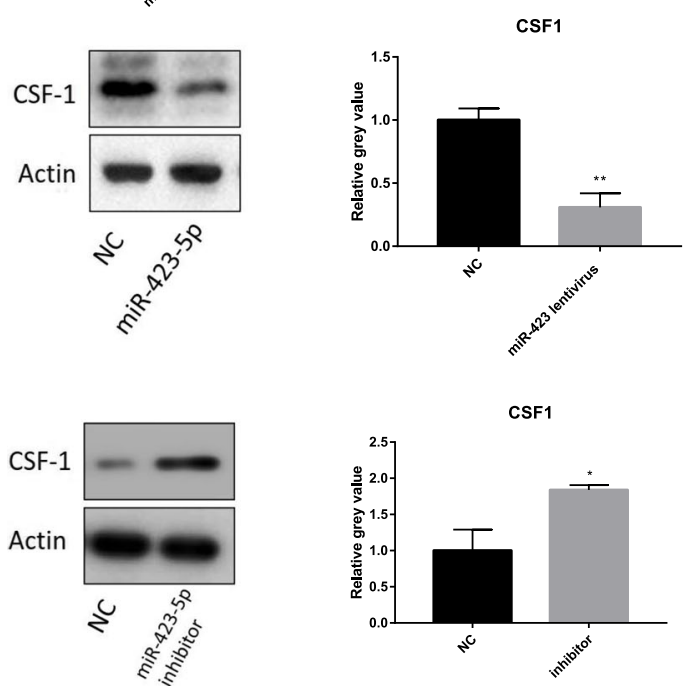

Fig. 1 a Transfection with the lentivirus or inhibitor caused hsa-miR423-5p expression to be increased or decreased in KGN cells, respectively. The black bars were controls, and the grey bar was hsamiR-423 transfection group or hsa-miR-423-5p inhibitor transfection group. ( $\left.{ }^{*} p<0.05\right)$. b The predicted sequences to which hsa-miR-423$5 p$ binds in the 3'-UTR of CSF1 are shown in yellow shadow. c HsamiR-423-5p negatively regulates the expression of CSF1. Hsa-miR423-5p overexpression led to reduced CSF1 expression, whereas the use of inhibitors led to increased CSF1 expression, in KGN cells. d Overexpression of hsa-miR-423-5p reduced the expression of CSF1 protein, and decreased expression of hsa-miR-423-5p increased the expression of CSF1 protein. The bar graphs indicate the mean \pm SEM. The black bars were controls, and the grey bar were hsa-miR-423 transfection groups or hsa-miR-423-5p inhibitor transfection groups ${ }^{*} p<0.05$, $\left.{ }^{* *} p<0.01\right)$ 
a

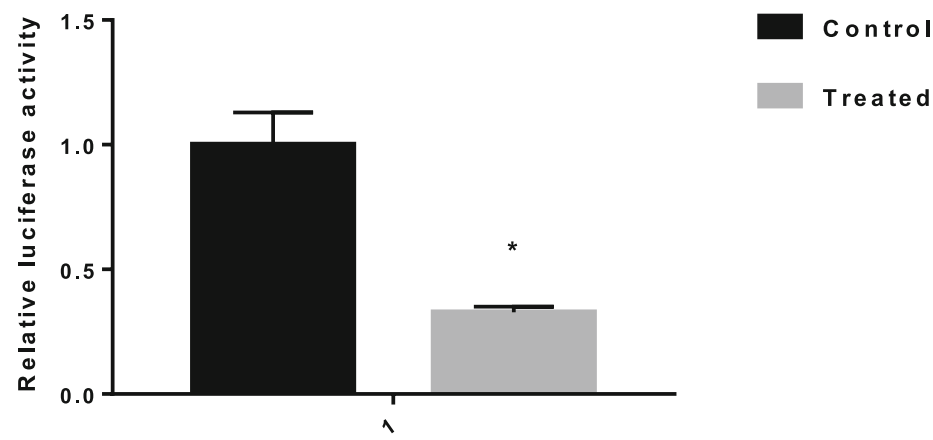

b

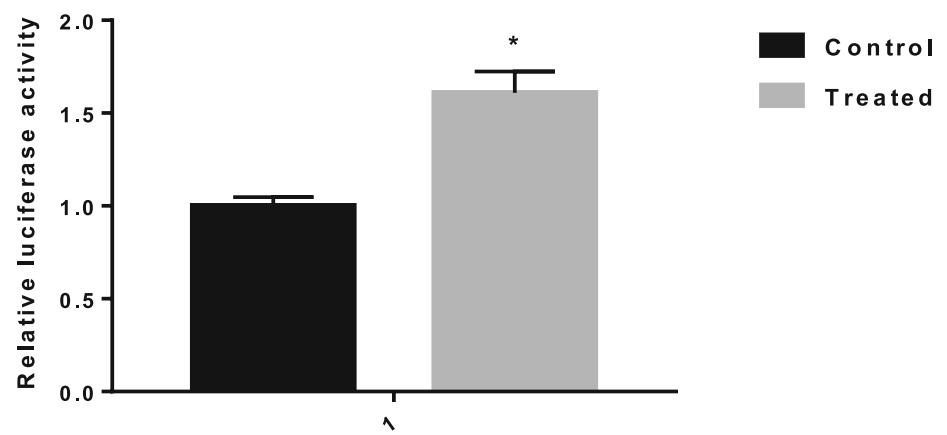

Fig. 2 CSF-1 is a target gene of hsa-miR-423-5p. a Firefly luciferase activity was significantly decreased in the hsa-miR-423-5p transfected KGN cells compare with the control cells. The black bar was control, and the grey bar was hsa-miR-423 transfection group. b Firefly luciferase activity was significantly increased in the hsa-miR-423-5p inhibitor transfected KGN cells compare with the control cells. The black bars was controls, and the grey bar was hsa-miR-423-5p inhibitor transfection group. The data are presented as the mean \pm SEM $\left({ }^{*} p<0.05\right)$

cell-cycle arrest, with the inhibition of cell proliferation brought about by impeding transition from the G1 to the $S$ phase of the cell cycle. By contrast, the hsa-miR423-5p inhibitor caused an increase in the number of cells in the $S$ phase $(P<0.01)$. The results of these investigations are summarized in Fig. 4.

\section{Hsa-miR-423-5p promotes the expression of CDKN1A}

Cyclin-dependent kinase inhibitor 1A (CDKN1A) is a negative regulator of the cell cycle. The expression of CDKN1A protein was significantly upregulated by hsamiR-423-5p overexpression, while its expression was downregulated by inhibited expression of hsa-miR-4235p (Fig. 5).

Hsa-miR-423-5p affects the secretion of $E_{2}$ in KGN cells The concentration of $E_{2}$ in the $K G N$ cell culture medium, as measured by ECLIA, decreased significantly $(P<0.05)$ after hsa-miR-423-5p overexpression (Fig. 6a). By contrast, the hsa-miR-423-5p inhibitor caused an increase in $\mathrm{E}_{2}$ levels in the KGN cell culture medium (Fig. 6b). These results indicated that hsa-miR-423-5p could affect the secretion of $\mathrm{E}_{2}$ from KGN cells.

\section{Discussion}

In the present study, we found that CSF1 is a target gene of hsa-miR-423-5p. Moreover, we demonstrated that hsa-miRNA-423-5p could influence cycle proliferation of KGN cells, and this effect may be achieved by affecting the expression of CDKN1A. Through measuring the $E_{2}$ concentration of cell culture medium, we show that the secretion of E2 in KGN cells affected by hsa-miR-423$5 \mathrm{p}$. These results suggest that the altered expression of hsa-miR-423-5p and its target gene CSF1 in ovarian granulosa cells maybe the reason of high ovarian response to exogenous gonadotropins.

Previous studies have shown that CSF1 is a target gene for a variety of miRNAs. For example, miR-1207-5p targeting CSF1 inhibits the implantation and metastasis of lung cancer [39]; miR-148b targets CSF1 and other genes that inhibit the development of breast cancer [40]; miR-142-3p targets CSF1 to induce the conversion of 

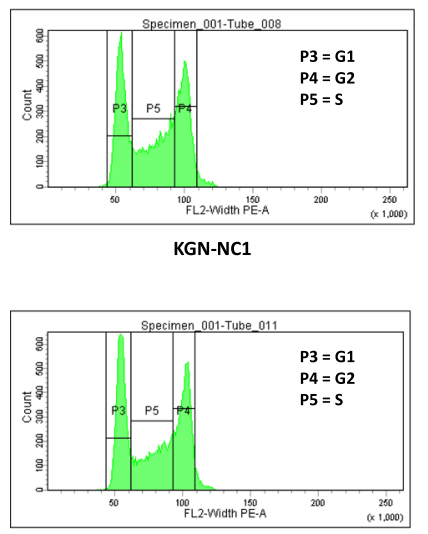

KGN-NC2

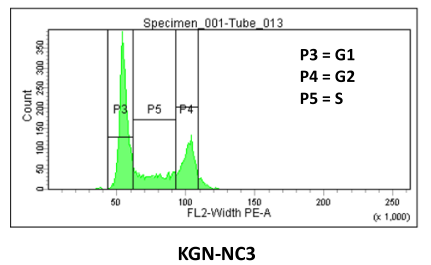

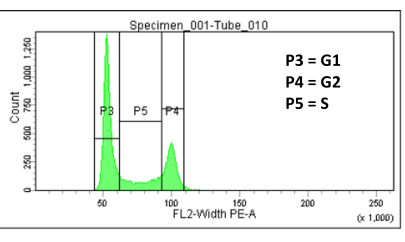

KGN-MIR1

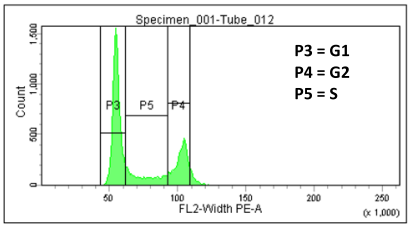

KGN-MIR2

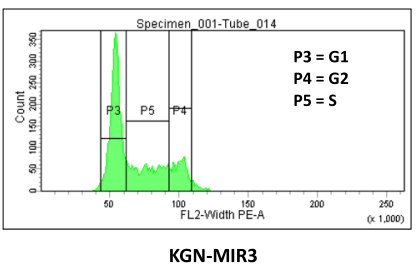

KGN-MIR3

b

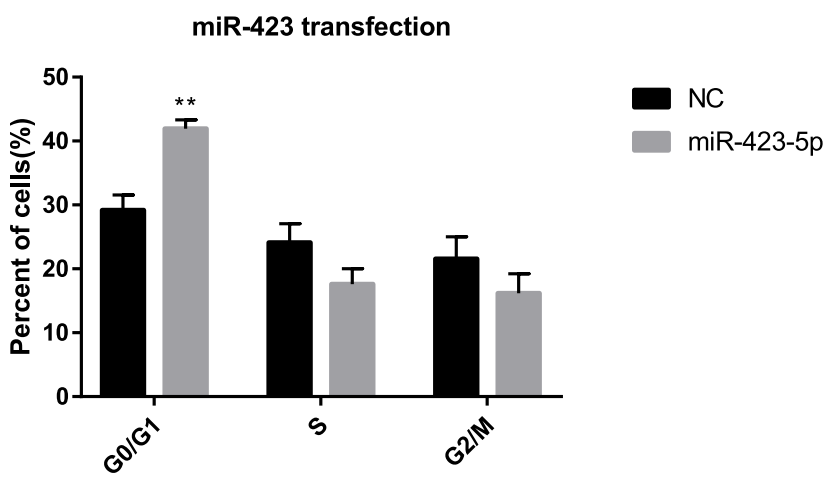

Fig. 3 Overexpression of hsa-miR-423-5p blocked the cell cycle progression of KGN cells. a Flow cytometric analysis showing the cell cycle distribution (G0/G1, S and G2/M phases) of KGN cells transfected with hsa-miR-423 lentivirus or the negative control (NC). b Bar graphs showing the percentages of cells in G0/G1, S and G2/M phases of the cell cycle after transfection with hsa-miR-423 lentivirus. The black bars were controls, and the grey bar were hsa-miR-423 transfection group. The bar graphs indicate the mean \pm SEM $\left({ }^{* *} p<0.01\right)$

monocytes to macrophages [41]; and miR-214 targets CSF1 to regulate the proliferation, invasion, and migration of gastric cancer cells [42]. To date, there have been no reports of miR-423-5p targeting CSF1, as we have shown in this study. We confirmed that CSF1 is a target gene of hsa-miR-423-5p for the first time.

Cytokines are small proteins that bind to receptors on the surfaces of cell membranes. They are involved in promoting cell growth and in regulating immune responses, as well as having a role in inflammatory reactions. Studies have shown that cytokines play important roles in follicular growth and embryonic development. Ovarian granulosa cells secrete a variety of cytokines to promote follicular growth, ovulation, hormone synthesis, and secretion [43-45]. Cytokine expression levels are also closely related to the maintenance of normal follicular development and to steroid hormone secretion in the ovary [46]. Colony stimulating factor 1 is an important cytokine that mainly acts on mononuclear macrophage cell lines, where it is involved in regulating their proliferation, differentiation, and function [47]. Previous studies have shown that CSF1 is also key to the regulation of female reproductive function. In this study, we showed that CSF1 was a target gene of miR-423-5p and that CSF1 most likely regulated ovarian reactivity to control ovarian stimulation by affecting the cell cycle and hormone secretion. 
a
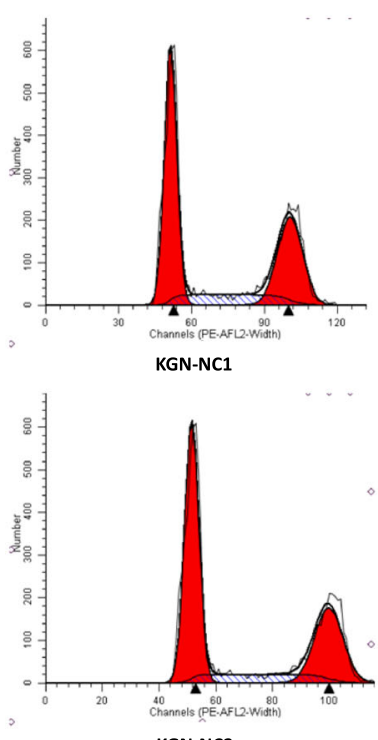

KGN-NC2

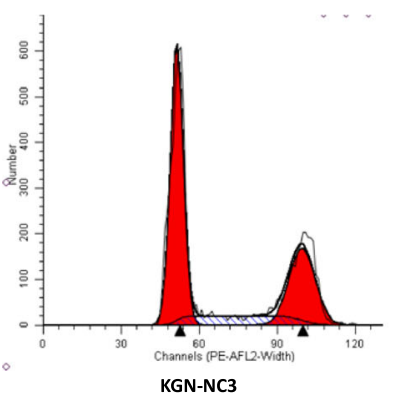

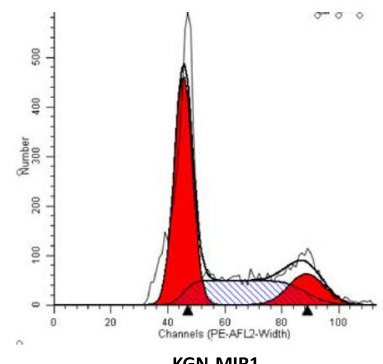
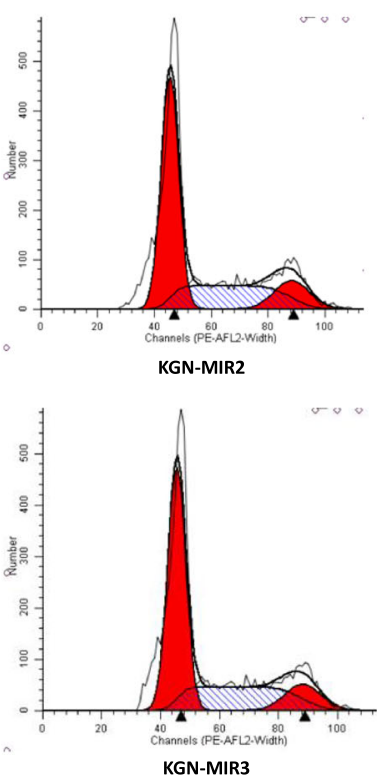

b

miR-423-5p inhibitor transfection

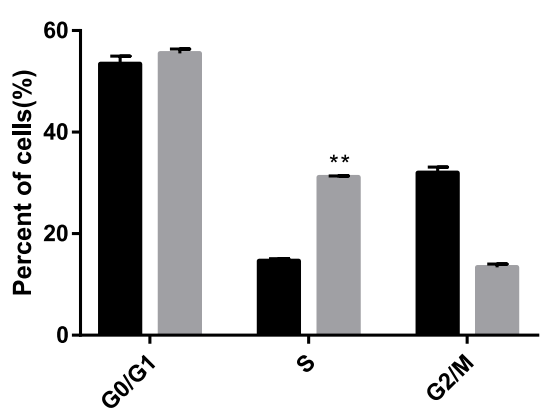

Fig. 4 Decreased expression of hsa-miR-423-5p enhanced cell cycle progression of KGN cells. a Flow cytometric analysis showing the cell cycle distribution (GO/G1, S and G2/M phases) of KGN cells transfected with hsa-miR-423-5p inhibitor or the negative control (NC). b Bar graphs showing the percentages of cells in G0/G1, S and G2/M phases of the cell cycle after transfection with hsa-miR-423-5p inhibitors. The black bars were controls, and the grey bar were hsa-miR-423-5p inhibitor transfection group. The bar graphs indicate the mean \pm SEM $\left({ }^{* *} p<0.01\right)$

Colony stimulating factor 1 secreted by ovarian granulosa cells through autocrine or paracrine routes. Once released, it binds to cell surface receptors and affects intracellular metabolism, oocyte meiosis, and follicular growth and maturation. As early as 1995, Nishimura et al. [48] first reported that CSF1 affected follicular development and ovulation in rats. A significant increase in the ovulation rate was observed in female rats after CSF1 treatment. Later Araki et al. [49] found that the number of ovulations, antral follicles, and mature follicles were lower in osteopetrotic (op/op) mutant mice when compared with normal litters. The op/op mice lack the coding region for the CSF1 gene and are completely devoid of CSF1. Moreover, the number of granulosa cells and the proliferative capacity of antral follicles were also 


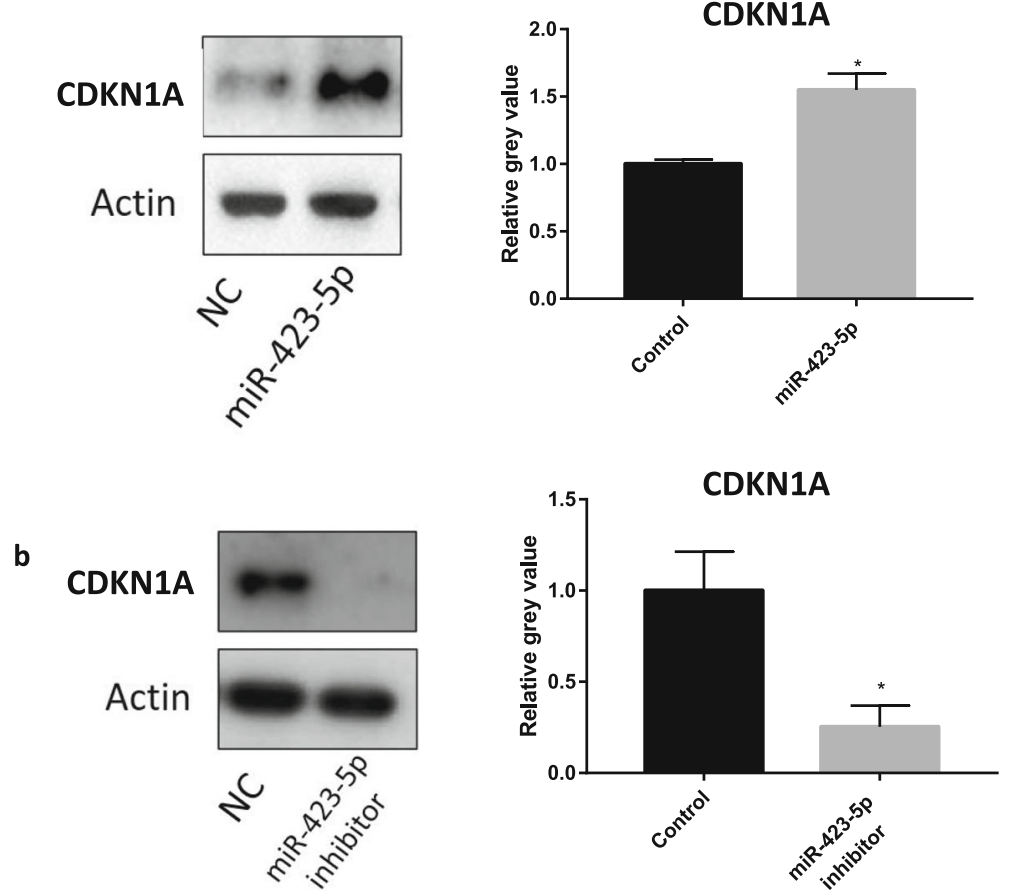

Fig. 5 Hsa-miR-423-5p affects the expression of CDKN1A protein. a The expression of CDKN1A protein was significantly upregulated by hsa-miR423-5p overexpression. $\mathbf{b}$ The expression of CDKN1A protein was downregulated by inhibited expression of hsa-miR-423-5p. The black bars were controls, and the grey bar were hsa-miR-423 transfection groups or hsa-miR-423-5p inhibitor transfection groups. The bar graphs indicate the mean \pm SEM. $\left({ }^{*} p<0.05\right)$

reduced in the op/op mice. When the researchers injected supplementary CSF1 into the op/op mice, the numbers of antral follicles, mature follicles, and granulosa cells around the follicle increased. Therefore, they concluded that CSF1 promoted ovarian granulosa cell proliferation and that it participated in regulating follicular production and ovulation. Cohen et al. [50] also observed a decrease in the ovulation rate of op/op mice. In 1997, researchers showed that CSF1 and its mRNA were expressed in human follicular fluid, and confirmed for the first time that CSF1 was involved in regulating human follicular development [51]. Soon after, Nishimura et al. [52] observed that the concentration of CSF1 in the serum increased gradually with the duration of COS, peaking between the egg retrieval day and 2 days later. Moreover, the concentration of CSF1 in the follicular fluid was significantly higher than that in the serum on the day of egg retrieval, and the concentration of CSF1 in the follicular fluid containing the ovum was higher than in that of the empty follicle. This study suggested that CSF1 may be involved in regulating egg maturation and ovulation. In other research, it was reported that the concentration of CSF1 in the follicular fluid was significantly higher than that in the serum. Furthermore, the expressions of CSF1 and its receptor were detected in isolated and cultured human luteinized granulosa cells, confirming that CSF1 is a key factor in follicular development [53].
The concentration of CSF1 in serum or follicular fluid is associated with ovarian response. Salmassi et al. [54] observed that there were difference in serum CSF1 levels depending on ovarian response during COS. They found that the higher a ovarian response with greater egg production was associated with a higher serum CSF1 concentration. Lei Huo [55] obtained similar results in patients undergoing IVF treatment, showing that the CSF1 concentration in the follicular fluid on the day human chorionic gonadotropin was given had a positive correlation with the number of eggs obtained. Thus, it is believed that CSF1 can affect ovarian reactivity and is related to egg maturation.

In our previous study [2], bioinformatics analysis of miRNAs with altered expression in ovarian hyperresponders revealed that the target genes of differential miRNAs were enriched in pathways such as cell-cycle regulation. In this study, we found that increased hsa-miR-423-5p can cause a large number of KGN cells to arrest in the G0/G1 phase, with the number of cells in $\mathrm{S}$ phase increased when hsa-miR-423-5p expression was inhibited. Although the percentage of $S$ phase cells was no statistical difference between miR-423-5p overexpression group and the negative control, it showed a downward tendency in the miR-423$5 \mathrm{p}$ overexpression group compared to the control. This result indicates that the expression level of hsa-miR-423$5 p$ in KGN cells does affect the cell cycle, which is 


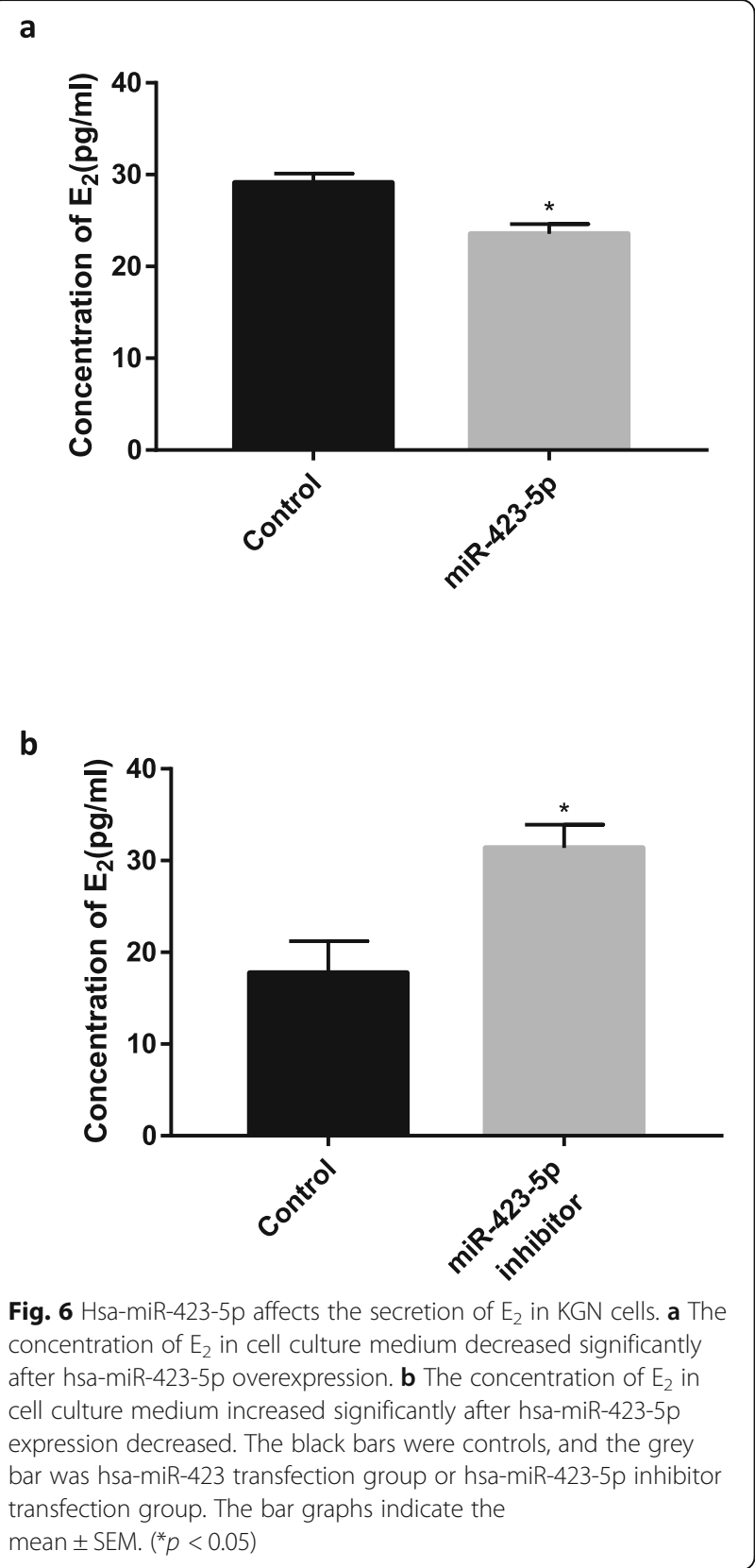

consistent with our previous study and confirms that hsamiR-423-5p is involved in the proliferation of KGN cells.

To further clarify the mechanism through which hsamiR-423-5p regulated the cell cycle, we examined the expression of CDKN1A protein. Cyclin-dependent kinase inhibitor $1 \mathrm{~A}$ is a negative regulator of the cell cycle that inhibits the activity of Cyclin-dependent kinase (CDK) and blocks cells in the G1 phase, thereby inhibiting cell proliferation [56]. When the hsa-miR-423-5p expression was increased, CDKN1A protein expression was upregulated. Conversely, when hsa-miR-423-5p expression was decreased, CDKN1A protein expression was downregulated. Thus, it appears that hsa-miR-423-5p may affect
CDK expression and induce cell arrest in the G0/G1 phase, thereby affecting cell proliferation. In patients with high ovarian response to COS, the decreased expression of hsa-miR-423-5p may lead to decreased inhibition of CSF1 and increased number of S phase cells. In turn, this could result in an abnormal high level of CSF1 in granulosa cells, causing the excessive proliferation of granulosa cells and the development of multiple follicles. This may explain cases of high ovarian response to COS. However, compared with the control group, the percentage of G0/ G1 phase cells in miR-423-5p inhibitor group was not significantly reduced. According to our analysis, the possible reason is that the sample size is too small to obtain statistically significant differences in both the $S$ and G0/G1 phases. More samples are required to fully profile the cell proliferation differences between the cells with different miR-423-5p expression in the future.

It is known that high levels of $E_{2}$ are usually associated with high ovarian response in patients [57]. In this study, the $E_{2}$ concentration was measured in the culture medium of KGN cells: concentrations decreased when hsa-miR-423$5 p$ expression increased and concentrations increased when intracellular hsa-miR-423-5p expression decreased. Study have shown that CSF1 can help FSH by promoting $\mathrm{E}_{2}$ secretion from ovarian granulosa cells and upregulating $\mathrm{FSH}$ receptor expression [58]. Therefore, we hypothesized that hsa-miR-423-5p overexpression inhibited CSF1 expression and led to a decrease in $\mathrm{E}_{2}$ secretion by KGN cells. This effect on hormone secretion was attenuated after hsa-miR423-5p was inhibited. Downregulation of hsa-miR-423-5p in patients with high ovarian response to COS may lead to an increase in the CSF1 concentration in granulosa cells, thereby stimulating excessive secretion of $E_{2}$ by cells.

Based on these findings, we can state that hsa-miR-423-5p may regulate the proliferation of ovarian granulosa cells and the secretion of $E_{2}$ within a proper range. It appears to do so by negatively regulating the expression of its target gene, CSF1, in ovarian granulosa cells. This is characterized by a normal ovarian response. In patients with a high ovarian response, however, hsa-miR-423-5p expression appears to be downregulated, such that the inhibition of CSF1 is weakened. In turn, this may lead to excessive CSF1 secretion, excessive granulosa cell proliferation, abnormal sensitivity to exogenous gonadotropins, simultaneous development of a large number of follicles being promoted, and abnormal $\mathrm{E}_{2}$ elevations. Together, these result in a high ovarian response.

To the best of our knowledge, this is the first study to have linked the expression of granulosa cell miRNAs to the secretion of CSF1. We found an upstream regulatory factor that causes changes in CSF1 concentrations in granulosa cells, thereby adding to current knowledge of the factors associated with ovarian reactivity. However, in this study, we only conducted a preliminary exploration of the mechanism through which miR-423-5p and 
its target gene, CSF1, regulate ovarian response. Further research is therefore needed to identify the signal pathway through which the miR-423-5p targeting of CSF1 regulates ovarian response. In addition, we will try to find suitable targeted inhibitors affecting miR-423-5p/ CSF1 pathway in vitro and in vivo to avoid high ovarian response as much as possible. If the research is successful, it may help prevent ovarian hyperstimulation syndrome (OHSS).

\section{Conclusion}

In summary, we present the novel finding that CSF1 is a target gene of hsa-miR-423-5p. Our results obtained on KGN cells suggest that hsa-miR-423-5p downregulation in the ovarian granulosa cells of patients with high ovarian response abnormally increases CSF1 expression. This may cause a massive proliferation of granulosa cells and an excessive secretion of $E_{2}$, which produce the high ovarian response. These findings are important for further studies on the mechanism of miRNA action in the human ovary.

\section{Supplementary information}

Supplementary information accompanies this paper at https://doi.org/10. 1186/s12958-020-00585-0.

\section{Additional file 1 .}

\section{Abbreviations}

COS: Controlled ovarian stimulation; IVF: In vitro fertilization; miRNA: MicroRNA; FSH: Follicle-stimulating hormone; LH: Luteinizing hormone; E2: Estradiol; qRT-PCR: Quantitative real-time polymerase chain reaction; ECLIA: Electro-chemiluminescence immunoassay; CSF1: Colony stimulating factor 1; CDKN1A: Cyclin-dependent kinase inhibitor 1A; CDK: Cyclin-dependent kinase; OHSS: Ovarian Hyper-stimulation Syndrome

\section{Acknowledgments}

The author would like to thank Professor Xu Wenming who work in the Second Hospital of West China University of Sichuan, for his help to provide KGN cells. We would also like to thank Yong Song, who studies at Michigan State University, for her help of obtaining the KGN cells.

\section{Authors' contributions}

XS: Project development, Experimental design, Data Collection, Data analysis, Manuscript writing; ZQ: Guidance for statistical analysis. ZJ: Data analysis. HJ: Data Collection. FJ: Manuscript editing. LYP: Guidance for experimental design. All the authors approved the final version of the paper for publication.

\section{Funding}

This project supported by the National Natural Science Foundation of China (Grant No.81571507) and by the Hunan Province Enterprise Technical Renovation Project Funding (2015).

\section{Availability of data and materials}

The datasets used and/or analysed during the current study are available from the corresponding author on reasonable request.

\section{Consent for publication}

All authors provided final approval of the version to be published and agree to be accountable for all aspects of the work in ensuring that questions.

\section{Competing interests}

The authors declare that they have no competing interests.

Received: 14 December 2019 Accepted: 27 March 2020

Published online: 07 April 2020

\section{References}

1. Rombauts L, Lambalk CB, Schultze-Mosgau A, van Kuijk J, Verweij P, Gates D, et al. Intercycle variability of the ovarian response in patients undergoing repeated stimulation with corifollitropin alfa in a gonadotropin-releasing hormone antagonist protocol. Fertil Steril. 2015;104(4):884-90 e2. https://doi. org/10.1016/j.fertnstert.2015.06.027.

2. Xie S, Batnasan E, Zhang Q, Li Y. MicroRNA expression is altered in Granulosa cells of ovarian Hyperresponders. Reprod Sci. 2016;23(8):1001-10. https://doi.org/10.1177/1933719115625849.

3. Yang H, Fu H, Wang B, Zhang X, Mao J, Li X, et al. Exosomal miR-423-5p targets SUFU to promote cancer growth and metastasis and serves as a novel marker for gastric cancer. Mol Carcinog. 2018. https://doi.org/10.1002/ mc.22838.

4. Liu J, Wang $X$, Yang $X$, Liu $Y$, Shi $Y$, Ren J, et al. miRNA423-5p regulates cell proliferation and invasion by targeting trefoil factor 1 in gastric cancer cells. Cancer Lett. 2014;347(1):98-104. https://doi.org/10.1016/j.canlet.2014.01.024.

5. Bartel DP. MicroRNAs: Genomics, biogenesis, mechanism, and function. Cell. 2004;116(2):281-97. https://doi.org/10.1016/S0092-8674(04)00045-5.

6. Ambros V. The functions of animal microRNAs. Nature. 2004;431(7006):3505. https://doi.org/10.1038/nature02871.

7. Dai A, Sun H, Fang T, Zhang Q, Wu S, Jiang Y, et al. MicroRNA-133b stimulates ovarian estradiol synthesis by targeting Foxl2. FEBS Lett. 2013; 587(15):2474-82. https://doi.org/10.1016/j.febslet.2013.06.023.

8. Fiedler SD, Carletti MZ, Hong X, Christenson LK. Hormonal regulation of MicroRNA expression in periovulatory mouse mural granulosa cells. Biol Reprod. 2008;79(6):1030-7. https://doi.org/10.1095/biolreprod.108.069690.

9. Macias S, Michlewski G, Caceres JF. Hormonal regulation of microRNA biogenesis. Mol Cell. 2009;36(2):172-3. https://doi.org/10.1016/j.molcel.2009. 10.006 .

10. Sang $Q$, Yao Z, Wang $H$, Feng $R$, Wang $H$, Zhao $X$, et al. Identification of microRNAs in human follicular fluid: characterization of microRNAs that govern steroidogenesis in vitro and are associated with polycystic ovary syndrome in vivo. J Clin Endocrinol Metab. 2013;98(7):3068-79. https://doi. org/10.1210/jc.2013-1715.

11. Xu S, Linher-Melville K, Yang BB, Wu D, Li J. Micro-RNA378 (miR-378) regulates ovarian estradiol production by targeting aromatase. Endocrinology. 2011;152(10):3941-51. https://doi.org/10.1210/en.2011-1147.

12. Yao G, Yin M, Lian J, Tian H, Liu L, Li X, et al. MicroRNA-224 is involved in transforming growth factor-beta-mediated mouse granulosa cell proliferation and granulosa cell function by targeting Smad4. Mol Endocrinol. 2010;24(3):540-51. https://doi.org/10.1210/me.2009-0432.

13. Wang M, Liu M, Sun J, Jia L, Ma S, Gao J, et al. MicroRNA-27a-3p affects estradiol and androgen imbalance by targeting Creb1 in the granulosa cells in mouse polycytic ovary syndrome model. Reprod Biol. 2017;17(4):295-304. https://doi.org/10.1016/j.repbio.2017.09.005.

14. Wu S, Sun H, Zhang Q, Jiang Y, Fang T, Cui I, et al. MicroRNA-132 promotes estradiol synthesis in ovarian granulosa cells via translational repression of Nurr1. Reprod Biol Endocrinol. 2015;13:94. https://doi.org/10.1186/s12958015-0095-z.

15. Ahn HW, Morin RD, Zhao H, Harris RA, Coarfa C, Chen ZJ, et al. MicroRNA transcriptome in the newborn mouse ovaries determined by massive parallel sequencing. Mol Hum Reprod. 2010;16(7):463-71. https://doi.org/10. 1093/molehr/gaq017.

16. Assou S, Al-edani T, Haouzi D, Philippe N, Lecellier CH, Piquemal D, et al. MicroRNAs: new candidates for the regulation of the human cumulusoocyte complex. Hum Reprod. 2013;28(11):3038-49. https://doi.org/10.1093/ humrep/det321.

17. Carletti MZ, Fiedler SD, Christenson LK. MicroRNA 21 blocks apoptosis in mouse periovulatory granulosa cells. Biol Reprod. 2010;83(2):286-95. https:// doi.org/10.1095/biolreprod.109.081448. 
18. Sirotkin AV, Laukova M, Ovcharenko D, Brenaut P, Mlyncek M. Identification of microRNAs controlling human ovarian cell proliferation and apoptosis. Cell Physiol. 2010;223(1):49-56. https://doi.org/10.1002/jcp.21999.

19. Yang $X$, Zhou Y, Peng S, Wu L, Lin HY, Wang S, et al. Differentially expressed plasma microRNAs in premature ovarian failure patients and the potential regulatory function of mir-23a in granulosa cell apoptosis. Reproduction. 2012;144(2):235-44. https://doi.org/10.1530/REP-11-0371.

20. Li D, Xu D, Xu Y, Chen L, Li C, Dai X, et al. MicroRNA-141-3p targets DAPK1 and inhibits apoptosis in rat ovarian granulosa cells. Cell Biochem Funct. 2017;35(4):197-201. https://doi.org/10.1002/cbf.3248.

21. Chen H, Liu C, Jiang H, Gao Y, Xu M, Wang J, et al. Regulatory role of miRNA-375 in expression of BMP15/GDF9 receptors and its effect on proliferation and apoptosis of bovine cumulus cells. Cell Physiol Biochem. 2017;41(2):439-50. https://doi.org/10.1159/000456597.

22. Du X, Zhang L, Li X, Pan Z, Liu H, Li Q. TGF-beta signaling controls FSHR signaling-reduced ovarian granulosa cell apoptosis through the SMAD4/ miR-143 axis. Cell Death Dis. 2016;7(11):e2476. https://doi.org/10.1038/cddis. 2016.379.

23. Nie $M$, Yu S, Peng S, Fang $Y$, Wang $H$, Yang $X$. miR-23a and miR-27a promote human granulosa cell apoptosis by targeting SMAD5. Biol Reprod. 2015:93(4):98. https://doi.org/10.1095/biolreprod.115.130690.

24. Chen X, Xie M, Liu D, Shi K. Downregulation of microRNA146a inhibits ovarian granulosa cell apoptosis by simultaneously targeting interleukin receptorassociated kinase and tumor necrosis factor receptorassociated factor 6. Mol Med Rep. 2015;12(4):5155-62. https://doi.org/10.3892/mmr. 2015.4036.

25. Choi Y, Qin Y, Berger MF, Ballow DJ, Bulyk ML, Rajkovic A. Microarray analyses of newborn mouse ovaries lacking Nobox. Biol Reprod. 2007;77(2): 312-9. https://doi.org/10.1095/biolreprod.107.060459.

26. Donadeu FX, Schauer SN, Sontakke SD. Involvement of miRNAs in ovarian follicular and luteal development. J Endocrinol. 2012;215(3):323-34. https:// doi.org/10.1530/JOE-12-0252.

27. Lei L, Jin S, Gonzalez G, Behringer RR, Woodruff TK. The regulatory role of dicer in folliculogenesis in mice. Mol Cell Endocrinol. 2010;315(1-2):63-73. https://doi.org/10.1016/j.mce.2009.09.021.

28. Liu HC, Tang Y, He Z, Rosenwaks Z. Dicer is a key player in oocyte maturation. J Assist Reprod Genet. 2010;27(9-10):571-80. https://doi.org/10. 1007/s10815-010-9456-X.

29. Ma J, Flemr M, Stein P, Berninger P, Malik R, Zavolan M, et al. MicroRNA activity is suppressed in mouse oocytes. Curr Biol. 2010;20(3):265-70. https:// doi.org/10.1016/j.cub.2009.12.042

30. Nagaraja AK, Andreu-Vieyra C, Franco HL, Ma L, Chen R, Han DY, et al. Deletion of dicer in somatic cells of the female reproductive tract causes sterility. Mol Endocrinol. 2008;22(10):2336-52. https://doi.org/10.1210/me. 2008-0142.

31. Suh N, Baehner L, Moltzahn F, Melton C, Shenoy A, Chen J, et al. MicroRNA function is globally suppressed in mouse oocytes and early embryos. Curr Biol. 2010;20(3):271-7. https://doi.org/10.1016/j.cub.2009.12.044.

32. Sinha PB, Tesfaye $D$, Rings F, Hossien M, Hoelker M, Held E, et al. MicroRNA$130 \mathrm{~b}$ is involved in bovine granulosa and cumulus cells function, oocyte maturation and blastocyst formation. J Ovarian Res. 2017;10(1):37. https:// doi.org/10.1186/s13048-017-0336-1.

33. Dzafic E, Stimpfel M, Virant-Klun I. Plasticity of granulosa cells: on the crossroad of stemness and transdifferentiation potential. J Assist Reprod Gen. 2013;30(10):1255-61. https://doi.org/10.1007/s10815-013-0068-0.

34. Rimon-Dahari N, Yerushalmi-Heinemann L, Alyagor L, Dekel N. Ovarian Folliculogenesis. Results Probl Cell Differ. 2016;58:167-90. https://doi.org/10. 1007/978-3-319-31973-5_7

35. Andersen CY, Ezcurra D. Human steroidogenesis: implications for controlled ovarian stimulation with exogenous gonadotropins. Reprod Biol Endocrin. 2014;12:128. https://doi.org/10.1186/1477-7827-12-128.

36. Havelock JC, Rainey WE, Carr BR. Ovarian granulosa cell lines. Mol Cell Endocrinol. 2004;228(1-2):67-78. https://doi.org/10.1016/j.mce.2004.04.018.

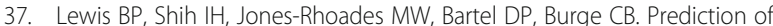
mammalian microRNA targets. Cell. 2003;115(7):787-98.

38. Livak KJ, Schmittgen TD. Analysis of relative gene expression data using real-time quantitative PCR and the 2(-Delta Delta C(T)) method. Methods. 2001;25(4):402-8. https://doi.org/10.1006/meth.2001.1262

39. Dang W, Qin Z, Fan S, Wen Q, Lu Y, Wang J, et al. miR-1207-5p suppresses lung cancer growth and metastasis by targeting CSF1. Oncotarget. 2016; 7(22):32421-32. https://doi.org/10.18632/oncotarget.8718.
40. Cimino D, De Pitta C, Orso F, Zampini M, Casara S, Penna E, et al. miR148b is a major coordinator of breast cancer progression in a relapse-associated microRNA signature by targeting ITGA5, ROCK1, PIK3CA, NRAS, and CSF1. FASEB J. 2013;27(3):1223-35. https://doi.org/10.1096/fj.12-214692.

41. Lagrange B, Martin RZ, Droin N, Aucagne R, Paggetti J, Largeot A, et al. A role for miR-142-3p in colony-stimulating factor 1-induced monocyte differentiation into macrophages. Biochim Biophys Acta. 2013;1833(8):193646. https://doi.org/10.1016/j.bbamcr.2013.04.007.

42. Wang YW, Shi DB, Chen X, Gao C, Gao P. Clinicopathological significance of microRNA-214 in gastric cancer and its effect on cell biological behaviour. PLoS One. 2014;9(3):e91307. https://doi.org/10.1371/journal.pone.0091307.

43. Chang HM, Qiao J, Leung PC. Oocyte-somatic cell interactions in the human ovary-novel role of bone morphogenetic proteins and growth differentiation factors. Hum Reprod Update. 2016;23(1):1-18. https://doi.org/ 10.1093/humupd/dmw039.

44. Kranc W, Budna J, Kahan R, Chachula A, Bryja A, Ciesiolka S, et al. Molecular basis of growth, proliferation, and differentiation of mammalian follicular granulosa cells. J Biol Regul Homeost Agents. 2017;31(1):1-8.

45. Buscher $\mathrm{U}$, Chen FC, Kentenich $\mathrm{H}$, Schmiady H. Cytokines in the follicular fluid of stimulated and non-stimulated human ovaries; is ovulation a suppressed inflammatory reaction? Hum Reprod. 1999;14(1):162-6.

46. Terranova PF, Rice VM. Review: cytokine involvement in ovarian processes. Am J Reprod Immunol. 1997;37(1):50-63.

47. Hume DA, Summers KM, Rehli M. Transcriptional regulation and macrophage differentiation. Microbiol Spectr. 2016;4(3). https://doi.org/10. 1128/microbiolspec.MCHD-0024-2015.

48. Nishimura K, Tanaka N, Ohshige A, Fukumatsu Y, Matsuura K, Okamura H. Effects of macrophage colony-stimulating factor on folliculogenesis in gonadotrophin-primed immature rats. J Reprod Fertil. 1995;104(2):325-30.

49. Araki M, Fukumatsu Y, Katabuchi H, Shultz LD, Takahashi K, Okamura H. Follicular development and ovulation in macrophage colony-stimulating factor-deficient mice homozygous for the osteopetrosis (op) mutation. Biol Reprod. 1996:54(2):478-84.

50. Cohen PE, Zhu L, Pollard JW. Absence of colony stimulating factor-1 in osteopetrotic (csfmop/csfmop) mice disrupts estrous cycles and ovulation. Biol Reprod. 1997;56(1):110-8.

51. Witt BR, Pollard JW. Colony stimulating factor-1 in human follicular fluid. Fertil Steril. 1997;68(2):259-64.

52. Nishimura K, Tanaka N, Kawano T, Matsuura K, Okamura H. Changes in macrophage colony-stimulating factor concentration in serum and follicular fluid in in-vitro fertilization and embryo transfer cycles. Fertil Steril. 1998;69(1):53-7.

53. Salmassi A, Zhang Z, Schmutzler AG, Koch K, Buck S, Jonat W, et al. Expression of mRNA and protein of macrophage colony-stimulating factor and its receptor in human follicular luteinized granulosa cells. Fertil Steril. 2005;83(2):419-25. https://doi.org/10.1016/j.fertnstert.2004.06.072.

54. Salmassi A, Mettler L, Jonat W, Buck S, Koch K, Schmutzler AG. Circulating level of macrophage colony-stimulating factor can be predictive for human in vitro fertilization outcome. Fertil Steril. 2010;93(1):116-23. https://doi.org/ 10.1016/j.fertnstert.2008.09.083.

55. Huo L. Analyzining the Effect of Macrophage Colony-Stimulating Factor and Interleukin-1 $\beta$ in Vitro Fertilization-embryo Transfer. Master's thesis: Zhengzhou University; 2011. http://new.oversea.cnki.net/KCMS/detail/detail. aspx? dbcode $=C M F D \& d b n a m e=C M F D 2012 \&$ filename $=1011213273$.nh\&uid $=$ WEEvREcwSIJHSIdRa1FhcEFLUmViSGFtTEZiTWFOZXc5VzVjYjdRcnMvND0= \$9A4hF_YAuvQ5obgVAqNKPCYcEjKensW4IQMovwHtwkF4VYPoHbKXJw!!\&v= MDAWNDFyQ1VSN3FmWStac0ZDcmdXcjdCVkYyNkg3Rz.

56. Raposo AE, Piller SC. Protein arginine methylation: an emerging regulator of the cell cycle. Cell Div. 2018;13:3. https://doi.org/10.1186/s13008-018-0036-2.

57. Huber M, Hadziosmanovic N, Berglund L, Holte J. Using the ovarian sensitivity index to define poor, normal, and high response after controlled ovarian hyperstimulation in the long gonadotropin-releasing hormone-agonist protocol: suggestions for a new principle to solve an old problem. Fertil Steril. 2013;100(5):1270-6. https://doi.org/10.1016/j.fertnstert.2013.06.049.

58. Zhang Z, Fang Q, Wang J. Involvement of macrophage colony-stimulating factor (M-CSF) in the function of follicular granulosa cells. Fertil Steril. 2008; 90(3):749-54. https://doi.org/10.1016/j.fertnstert.2007.06.098.

\section{Publisher's Note}

Springer Nature remains neutral with regard to jurisdictional claims in published maps and institutional affiliations. 